\title{
$k_{\text {trans }}$ as a quantitative indicator of calf muscle perfusion at peak exercise
}

\author{
David Lopez ${ }^{1 *}$, Patrick Antkowiak², Craig H Meyer ${ }^{2,3}$, Frederick H Epstein ${ }^{2}$, Christopher M Kramer ${ }^{1,3}$ \\ From 17th Annual SCMR Scientific Sessions \\ New Orleans, LA, USA. 16-19 January 2014
}

\section{Background}

Quantitative contrast enhanced MRI (CE-MRI) may be valuable for calf perfusion assessment in peripheral arterial disease (PAD). The Kety equation describes the dynamic relationship between the concentration of gadolinium (Gd) in tissue and in arterial blood. $k_{\text {trans }}$ is the rate at which Gd enters the interstitial space and it is determined by blood flow $(F)$ as well as the $\mathrm{Gd}$ extraction rate $(E)$. We aimed to measure $k_{\text {trans }}$ at peak exercise in healthy (NL) and PAD subjects.

\section{Methods}

Seven NL (age $53 \pm 11$, ankle brachial index (ABI) $1.0 \pm$ 0.1 , exercise time (ET) $353 \pm 241 \mathrm{~min}$ ) and 2 PAD subjects (age $80 \pm 2$, ABI $0.65 \pm 0.05$, ET $287 \pm 67 \mathrm{~min}$ ) were studied. A saturation recovery dual-contrast spoiled gradient echo (GRE) sequence was utilized to acquire the arterial input function (AIF) and muscle tissue function (TF). The pulse sequence was tested against $\mathrm{Gd}$ phantoms. AIF inversion time $(\mathrm{TI})=10 \mathrm{msec}$. TF $\mathrm{TI}$ $300 \mathrm{msec}$. Other parameters included delay between excitation pulses, $3.5 \mathrm{msec}$, matrix $=128 \times 128, \mathrm{FOV}=180 \times$ $180 \mathrm{~mm}, 8 \mathrm{~mm}$ thick, $\mathrm{FA}=15^{\circ}, \mathrm{TR}=768 \mathrm{msec}, \mathrm{TE}=1.43$ msec. A proton density image was acquired for signal normalization, $\mathrm{FA}=5^{\circ}$. Subjects exercised using an MRI-safe plantar flexion ergometer until exhaustion in a Siemens Trio 3T scanner. At peak exercise 75 non-ECG-gated GRE measurements were obtained while infusing $0.1 \mathrm{mmol} / \mathrm{kg}$ of Gd-DTPA at $4 \mathrm{cc} / \mathrm{s}$. Regions of interest were drawn on the muscle of interest and its feeding artery on the TF and AIF slices, respectively. Bloch equation modeling was performed to convert signal intensity into Gd-DTPA concentration. The AIF was fit to a gamma-variate function with an exponential washout term. Constrained Kety model deconvolution of the AIF from the TF was performed to calculate $k_{\text {trans }}$ using a Levenberg-Marquardt nonlinear least squares optimization implemented in Matlab.

\section{Results}

Gd phantom analysis showed good correlation between the theoretical and measured Gd concentrations (Figure 1A). A representative TF curve is shown in Figure 1B.

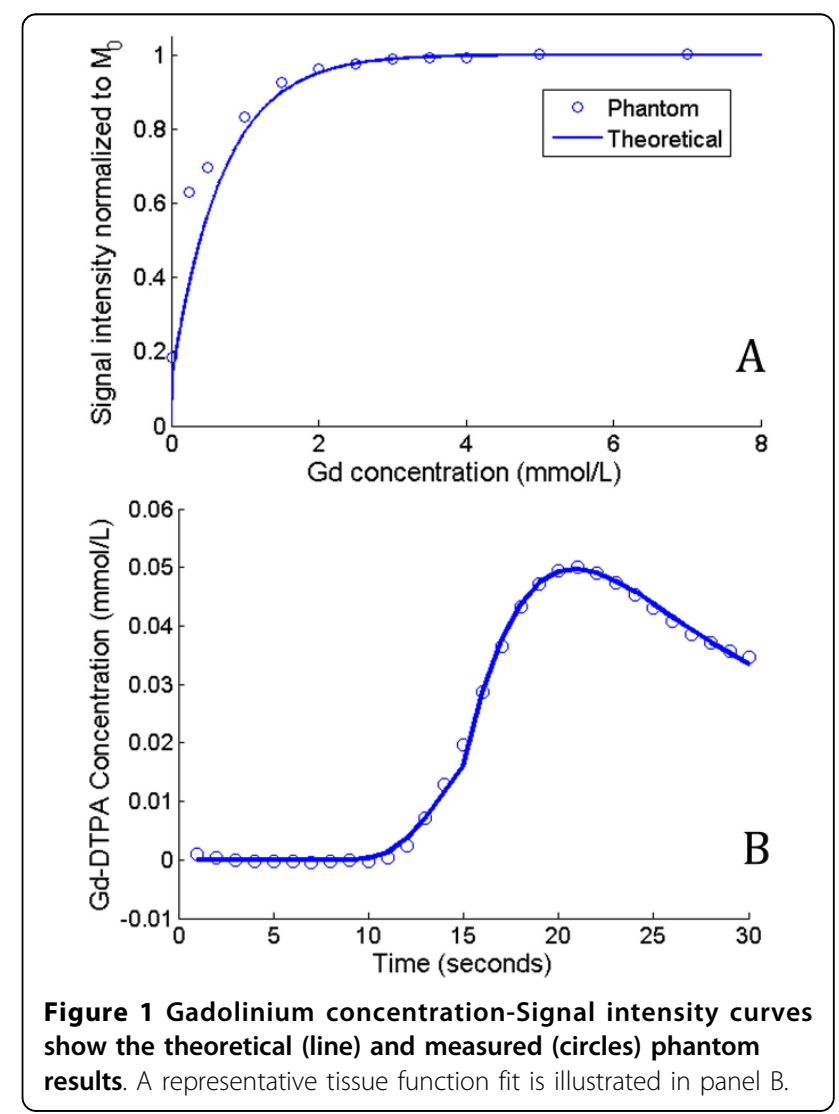

${ }^{1}$ Medicine, University of Virginia, Charlottesville, Virginia, USA

Full list of author information is available at the end of the article 

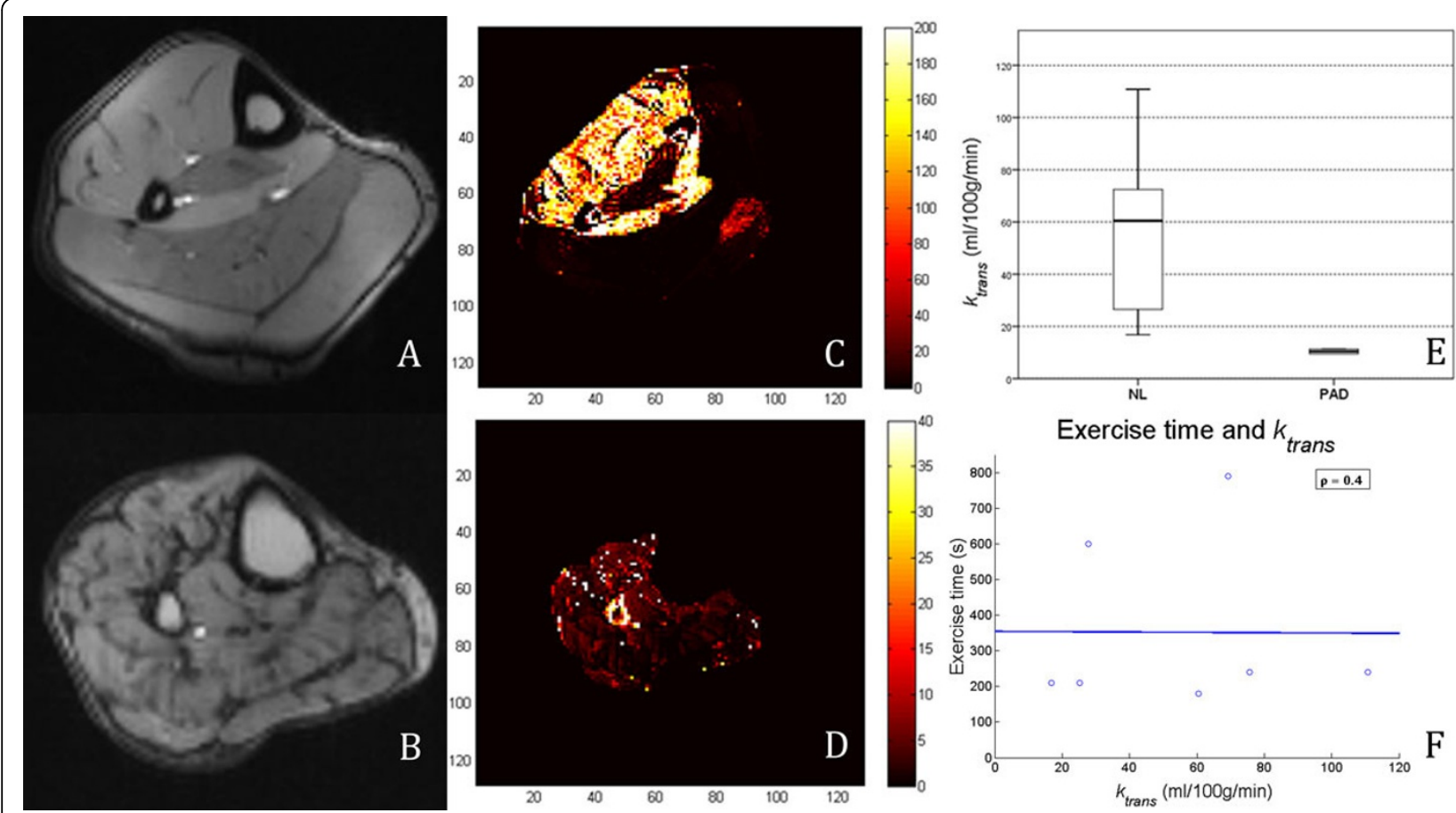

Figure 2 Representative GRE images at peak intensity of NL (A) and PAD (B) volunteers. Pixel maps illustrate the differences in $k_{\text {trans }}$ values between NL (C) and PAD (D). Box plot shows the $k_{\text {trans }}$ distribution (E). Note the lack of correlation between exercise time and $k_{\text {trans }}$. GRE $=$ gradient echo; $\mathrm{NL}=$ healthy volunteers; $\mathrm{PAD}=$ peripheral arterial disease patients; $\rho=$ Spearman's correlation.

Representative GRE images and calculated pixel maps are illustrated in Figure 2A-2D. Mean $k_{\text {trans }}$ was $55.1 \pm 31.3$ and $10.4 \pm 1.3 \mathrm{ml} / 100 \mathrm{~g} / \mathrm{min}$ in NL and PAD respectively (Figure 2E). There was no correlation between exercise duration and $k_{\text {trans }}$ in NL subjects (Figure 2F).

\section{Conclusions}

This pilot study shows that quantitative CE-CMR at peak exercise is feasible. $k_{\text {trans }}$ does not equal blood flow, but instead is a surrogate marker of perfusion modulated by $F$ and $E$. Preliminarily, it appears to differentiate normals from PAD as the latter is quite low in PAD. Thus it may become a valuable quantitative parameter for testing novel PAD therapies.

\section{Funding}

T32 EB003841 (DL), NIH HL075792 (CMK).

\section{Authors' details}

${ }^{1}$ Medicine, University of Virginia, Charlottesville, Virginia, USA. ${ }^{2}$ Biomedical Engineering, University of Virginia, Charlottesville, Virginia, USA. ${ }^{3}$ Radiology and Medical Imaging, University of Virginia, Charlottesville, Virginia, USA.
Published: 16 January 2014

doi:10.1186/1532-429X-16-S1-P27

Cite this article as: Lopez et al.: $k_{\text {trans }}$ as a quantitative indicator of calf muscle perfusion at peak exercise. Journal of Cardiovascular Magnetic Resonance 2014 16(Suppl 1):P27.

Submit your next manuscript to BioMed Central and take full advantage of:

- Convenient online submission

- Thorough peer review

- No space constraints or color figure charges

- Immediate publication on acceptance

- Inclusion in PubMed, CAS, Scopus and Google Scholar

- Research which is freely available for redistribution 